\title{
Comparison of the palatability of some compound feeds with different water content by tests on goats
}

\author{
P Morand-Fehr, J Hervieu \\ INRA, station de Nutrition et Alimentation de IINA-PG, 16, rue Claude-Bernard, \\ 75231 Paris Cedex 05, France
}

In comparison with other ruminants, goats appear to be very sensitive to the palatability of feeds (Mac Cammon-Feldman et al, 1981). They can be used in short-time period tests to discriminate concentrate feeds according to their level of palatability (Morand-Fehr and Hervieu, 1988). To assess the palatability of more kinds of feeds, we tried to adapt the test method for dry feeds to humid complete feeds.

The test conditions for accurately discriminating the palatability of 2 dry concentrate feeds were defined by Morand-Fehr et al (1987). To compare 2 feeds, 4 boxes ( 2 per feed) containing $200 \mathrm{~g}$ dry feed were presented to 14 goats over a $4 \times 30 \mathrm{~s}$ period. To compare the 4 feeds, 6 tests were carried out in a latin-square design by comparing the 6 possible combinations of feeds. The relative palatability of each feed was the average quantity ingested in all the tests of a series. The same method was used with humid feeds. The same quantity of dry matter $(176 \mathrm{~g})$ from humid $(75 \% \mathrm{DM})$ and dry $(88 \% \mathrm{DM})$ feed was put in each box. The standard feed (DM\%) contained $20 \%$ dehydrated beet pulp $60 \%$ barley and $20 \%$ soya oilmeal. To constitute humid feed, dehydrated beet pulp was rehydrated by adding $875 \mathrm{~g}$ water $/ \mathrm{kg}$. To compare feeds of different palatability we added $0,2,5$ or $10 \%$ of a low-palatability meat meal (oxidized flavor, peroxide index $=22$ ) to standard feeds $\mathrm{D}(\mathrm{dry})$ or $\mathrm{H}$ (humid) in 2 series of tests.

The average quantity ingested of raw feed per test was (1st series): $D_{0}: 179 a ; D_{2}$ : $99 \mathrm{~b}$; $D_{5}: 40^{c} ; D_{10}: 10^{c} ; H_{0}: 207 a ; H_{2}: 99 b ; H_{5}$ : 43c; $H_{10}: 5^{c}$ (2nd series); $D_{0}$ : 204a; $D_{2}$ : 128b; $\mathrm{D}_{5}: 51 \mathrm{c} ; \mathrm{D}_{10}: 26 \mathrm{c} ; \mathrm{H}_{0}: 233^{\mathrm{a}} ; \mathrm{H}_{2}$ : 105b; $\mathrm{H}_{5}: 48 \mathrm{c} ; \mathrm{H}_{10}: 18^{\mathrm{c}}$.

In this trial, the level of intake in goats seemed to be more related to raw matter than DM but that will have to be confirmed with larger scale humidity contents. The presence of meat meal in a blend decreased its palatability more when contents were between $0-2 \%$ ( $49 \mathrm{~g}$ less per point of increase) than between 5-10\% (6 g less only). The drop in palatability for humid or dry feeds is very close. Thus goats are as sensitive to the palatability of a humid compound feed containing $75 \%$ $\mathrm{DM}$ as to that of a dry feed containing $88 \%$ DM. The difference between 2 feeds is detected in the same manner whether the feeds are humid or dry. Consequently the tests for discriminating the palatability of 2 ingredients could be carried out at different levels of humidity, which would extend the area of application.

Mac Cammon-Feldman B, Van Soest PJ, Harvatly P, Mac Dowell RE (1981) Cornell Intern Agric Mimeo 88. Cornell Univ, Ithaca, NY

Morand-Fehr P, Hervieu J, Legendre D, Gutter A, Del Tedesco L (1987) Ann Zootech 36, 324

Morand-Fehr P, Henvieu J (1988) Reprod Nutr Dev 28, 101-102 